\title{
Complete III Cranial Nerve Palsy in a Leather Worker: An Unusual Case Report
}

\author{
Adriano Magli*, Elisabetta Chiariello Vecchio \\ Pediatric Eye Department, University of Salerno, Salerno, Italy \\ Email: ${ }^{*}$ amagli@unisa.it
}

Received 26 April 2014; revised 23 June 2014; accepted 25 July 2014

Copyright (C) 2014 by authors and Scientific Research Publishing Inc.

This work is licensed under the Creative Commons Attribution International License (CC BY). http://creativecommons.org/licenses/by/4.0/

(c) (i) 0pen Access

\section{Abstract}

This case report describes features and surgical management in one patient that developed a worsening total III cranial nerve palsy in his right eye. Our 45 year-old male patient worked for about 25 years in leather tanning industry. He underwent medical history, routine blood test, eye exams that included visual acuity measurement, slit-lamp examination, dilated retinal biomicroscopy and indirect ophthalmoscopy, fundus photography, tonometry, corneal pachymetry, Krimsky test, oculomotor examination and eye deviation surgery. On examination of the fellow eye wasn't found any disease. Stroke, aneurysm and intracerebral causes of third nerve palsy were excluded, and medical history was negative for diabetes, cardiovascular disease, trauma, neurological disease unless two previous polyneuropathies episodes and one herpetic keratitis episode. Result of any neuroimaging studies were recorded (Our patients performed in hospital CT, MRI and MRI angiography and all the testes were normal). To our knowledge third cranial nerve palsy has never been observed in literature in leather workers. In conclusion, it is important for ophthalmologists to evaluate carefully work history and lifestyle persons and plan the surgical approach focusing the different characteristics of these patients.

\section{Keywords}

Cranial Nerve Palsy, Leather Worker, Acquired Paralysis

\section{Introduction}

Third cranial nerve palsy is a disorder characterized by ptosis (due to levator palpebrae superioris muscle palsy), eye abduction because the lateral rectus (innervated by the sixth cranial nerve) maintains muscle tone in com parison to the paralyzed medial rectus, eye downward, because the superior oblique (innervated by the trochlear cranial nerve), is unantagonized by the paralyzed superior rectus and inferior oblique, and finally complete pa-

\footnotetext{
"Corresponding author.
} 
ralytic mydriasis.

So a complete Oculomotor nerve palsy will result in a characteristic down and out position in the affected eye. Oculomotor palsy can depend by several different conditions, congenital or acquired.

The origins of the vast majority of congenital oculomotor palsies are idiopathic.

The origins of the acquired oculomotor palsy are: vascular disorders such as diabetes, heart disease, atherosclerosis and aneurysm, particularly of the posterior communicating artery, space occupying lesions (both malignant and non-malignant), trauma, inflammation, infection, demyelinating disease or complication of neurosurgery [1] [2].

To our knowledge third cranial nerve palsy has never been observed in leather workers.

The objective of this paper is to describe an unusual case of complete III cranial nerve palsy in a leather worker, finding the possible causes.

\section{Case Presentation}

A 45 year-old Caucasian man that worked for about 25 years in leather tanning industry was referred, in the beginning, to The University of Napoli “Federico II”, and afterwards to The University of Salerno for evaluation and treatment of complete third nerve cranial palsy.

This disease had never been described in any previously published description in leather worker. He started noticing worsening ptosis, diplopia and blurry vision for several days in his right eye (Figure 1).

Over the next days and months it progressed. No recent trauma. No heart or vasculopathic diseases, he is not diabetic. He did not complain of headache or pain. He has no family or personal history of cranial nerve palsy and no neurological disease unless two previous polyneuropathies episodes and one herpetic keratitis episode. He did not have an history of vasculopathic risk factors as hypercholesterolemia or hypertension. Our patient performed several neuroimaging studies in hospital (CT, MRI with gadolinium and MRI angiography and all testes were normal).

The patient underwent several blood tests (included erythrocyte sedimentation rate, $\mathrm{C}$ reactive protein, acetylcoline receptor test) and motor conduction velocity (within normal limits). He underwent eye exams that included visual acuity measurement, slit-lamp examination, dilated retinal biomicroscopy and indirect ophthalmoscopy, fundus photography, tonometry, corneal pachymetry, Krimsky test, oculomotor examination and eye deviation surgery. On examination of the fellow eye wasn't found any disease.

On first examination his best corrected visual acuity was in his right eye 0.1 logMAR and in his left eye measured 0 logMAR.

Krimsky test in his right eye was -70 TR. Amplitude of the right eyelid was $4 \mathrm{~mm}$, excursions of eyelid $4 \mathrm{~mm}$, normal in his left eye. He presented complete paralytic mydriasis.

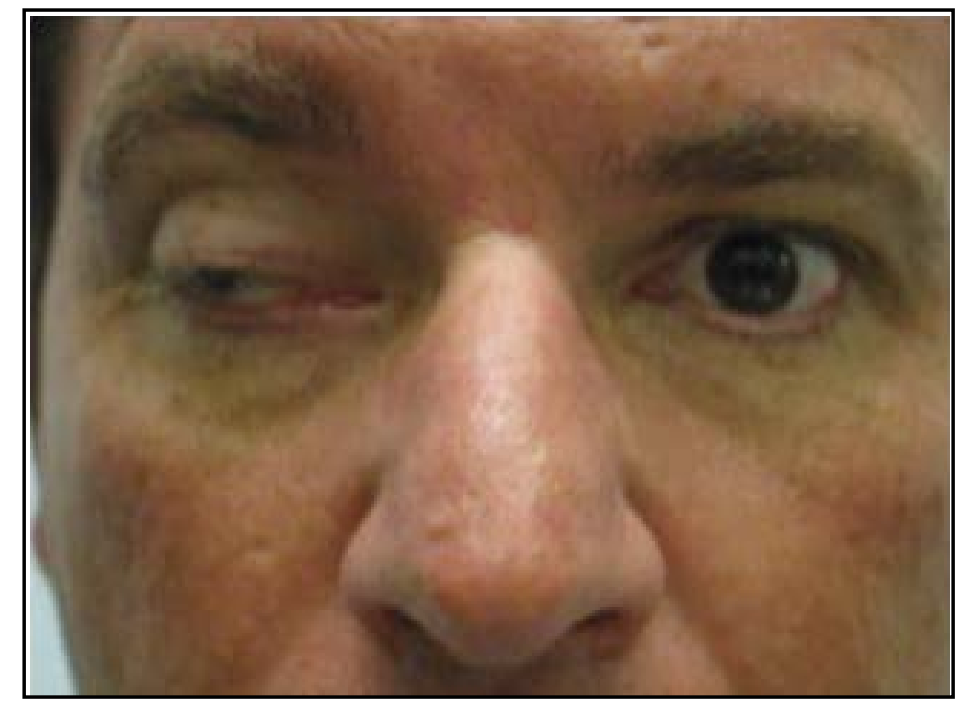

Figure 1. III cranial nerve palsy before the surgery: facial features. 
His right eye presented total deficit of horizontal and vertical movements (with residual abduction). Extraocular motility was full in all fields of gaze in his left eye. On external exam he demonstrated head turned to the left and chin up. His ocular past history was negative. No abnormalities findings on anterior segment. Dilated fundus exam was performed and was normal in OU.

\section{Discussion}

First treatment of this patient consisted of transposition of superior rectus, inferior rectus on medial rectus; sparring blood vessel and resection medial rectus (3 mm) (Figure 2).

After six years our patient presented improvement of ptosis (amplitude of the right eyelid was $4 \mathrm{~mm}$, excursions of eyelid $8 \mathrm{~mm}$ ) and Krimsky test-55 TR. Treatment of this patient consisted of transposition of superior oblique with anchor on the medial rectus, further resected and lateral rectus free tenotomy. Simultaneously, we performed frontal suspension for correction of ptosis (Figure 3).

On control he presented improvement of Krimsky test ( $-20 \mathrm{TR})$, IOP OU was $9 \mathrm{mmHg}$, corneal pachymetry in right eye was $528 \mu \mathrm{m}$, corneal pachymetry in left eye was $535 \mu \mathrm{m}$.

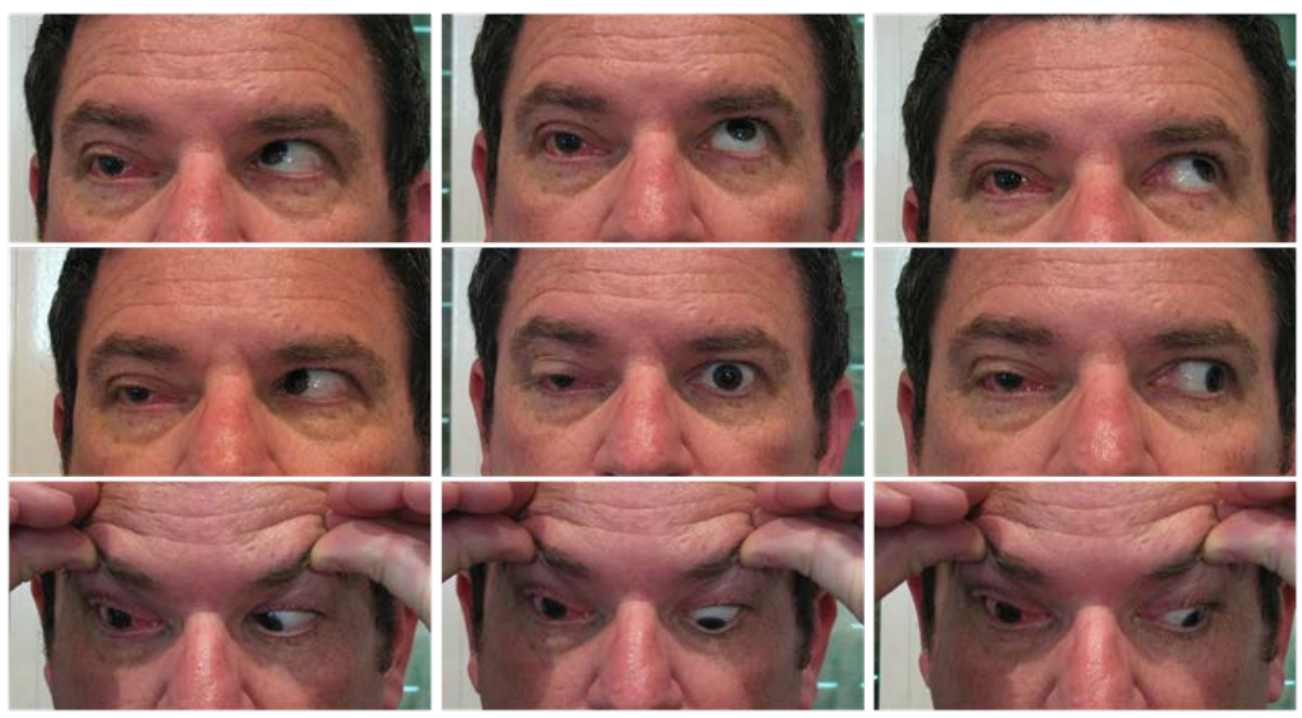

Figure 2. All fields of gaze after the first surgery.
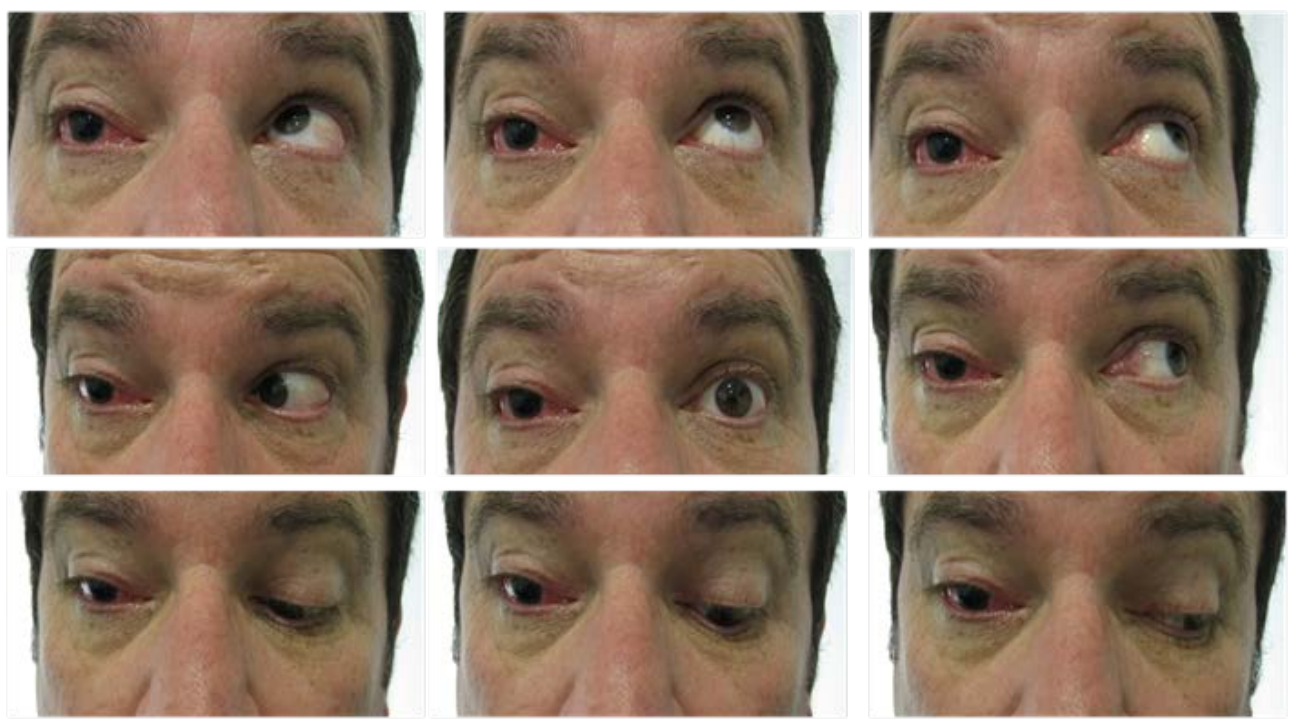

Figure 3. All fields of gaze after the second surgery. 
In literature there are very few papers about neurological disease in leather worker [3] [4] [5], and no paper about third cranial nerve palsy. In 1978 Buiatti et al. [6] reported an interesting manuscript about the relationship between clinical and electromyographic findings and exposure to solvents, in shoe and leather workers. He showed how the MCV (motor conduction velocity) is reduced with increasing the years of exposure to solvents.

In summary, to our known this is the first report to describe third cranial nerve palsy in leather worker. The correlation solvent-neuropathy is documented and is directly proportional to the exposure period. However, due to the wide variety of compositions and concentrations of chemical solvents available on the market it is impossible to identify the exact role that plays every single substance.

The study of the cause-effect relationship is also particularly difficult because of the short half-life of the solvents and their low solubility. Besides the exams are very specific and often very expensive.

\section{Conclusion}

In our patient the III cranial nerve palsy is monolateral, however chemical solvents have a systemic spread so we expected a bilateral involvement. Probably unilateral involvement is explained by the previous episode of herpetic keratitis. It is known that varicella-zoster virus (VZV) remains in the nerve ganglia for life. Chemical solvents may have reactivated the virus that is known to have spread unilateral. Finally, it is important for ophthalmologists to evaluate carefully extraocular motility and plan the surgical approach focusing the different characteristics of these patients. In acquired paralysis of the third pair of cranial nerves the transposition of superior oblique with anchor on the medial rectus, further resected and lateral rectus free tenotomy is probably the best choice.

\section{Acknowledgements}

Pictures are reproduced with kind permission of the patient.

\section{Conflict of Interest}

The authors do not have any financial conflict of interest in the subject matter in the manuscript. The study was performed with informed consent and following all the guidelines for experimental investigations required by the Institutional Review Board or Ethics Committee of which all authors are affiliated.

\section{References}

[1] Czyz, C.N., Bacon, T.S., Petrie, T.P., Justice, J.D. and Cahill, K.V. (2013) Isolated, Complete Paralytic Mydriasis Secondary to Herpes Zoster Ophthalmicus. Practical Neurology, 13, 183-184. http://dx.doi.org/10.1136/practneurol-2012-000365

[2] Najafi, M.R. and Mehrbod, N. (2012) Isolated Third Nerve Palsy from Mild Closed Head Trauma. Archives of Iranian Medicine, 15, 583-584.

[3] Hawkes, C.H., Cavanagh, J.B. and Fox, A.J. (1989) Motoneuron Disease: A Disorder Secondary to Solvent Exposure? Lancet, 1, 73-86. http://dx.doi.org/10.1016/S0140-6736(89)91430-X

[4] Cavalleri, A. and Cosi, V. (1978) Polyneuritis Incidence in Shoe Factory Workers: Cases Report and Etiological Considerations. Archives of Environmental Health, 33, 192-197. http://dx.doi.org/10.1080/00039896.1978.10667333

[5] Hawkes, C.H. and Fox, A.J. (1981) Motor Neurone Disease in Leather Workers. Lancet, 1, 507. http://dx.doi.org/10.1016/S0140-6736(81)91900-0 6

[6] Buiatti, E., Cecchini, S., Ronchi, O., Dolara, P. and Bulgarelli, G. (1978) Relationship between Clinical and Electromyographic Findings and Exposure to Solvents, in Shoe and Leather Workers. British Journal of Industrial Medicine, 35, 168-173. 
Scientific Research Publishing (SCIRP) is one of the largest Open Access journal publishers. It is currently publishing more than 200 open access, online, peer-reviewed journals covering a wide range of academic disciplines. SCIRP serves the worldwide academic communities and contributes to the progress and application of science with its publication.

Other selected journals from SCIRP are listed as below. Submit your manuscript to us via either submit@scirp.org or Online Submission Portal.
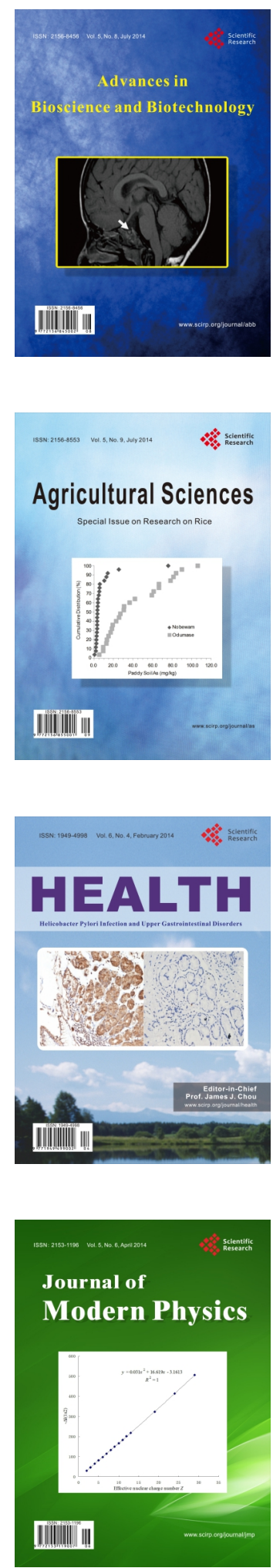
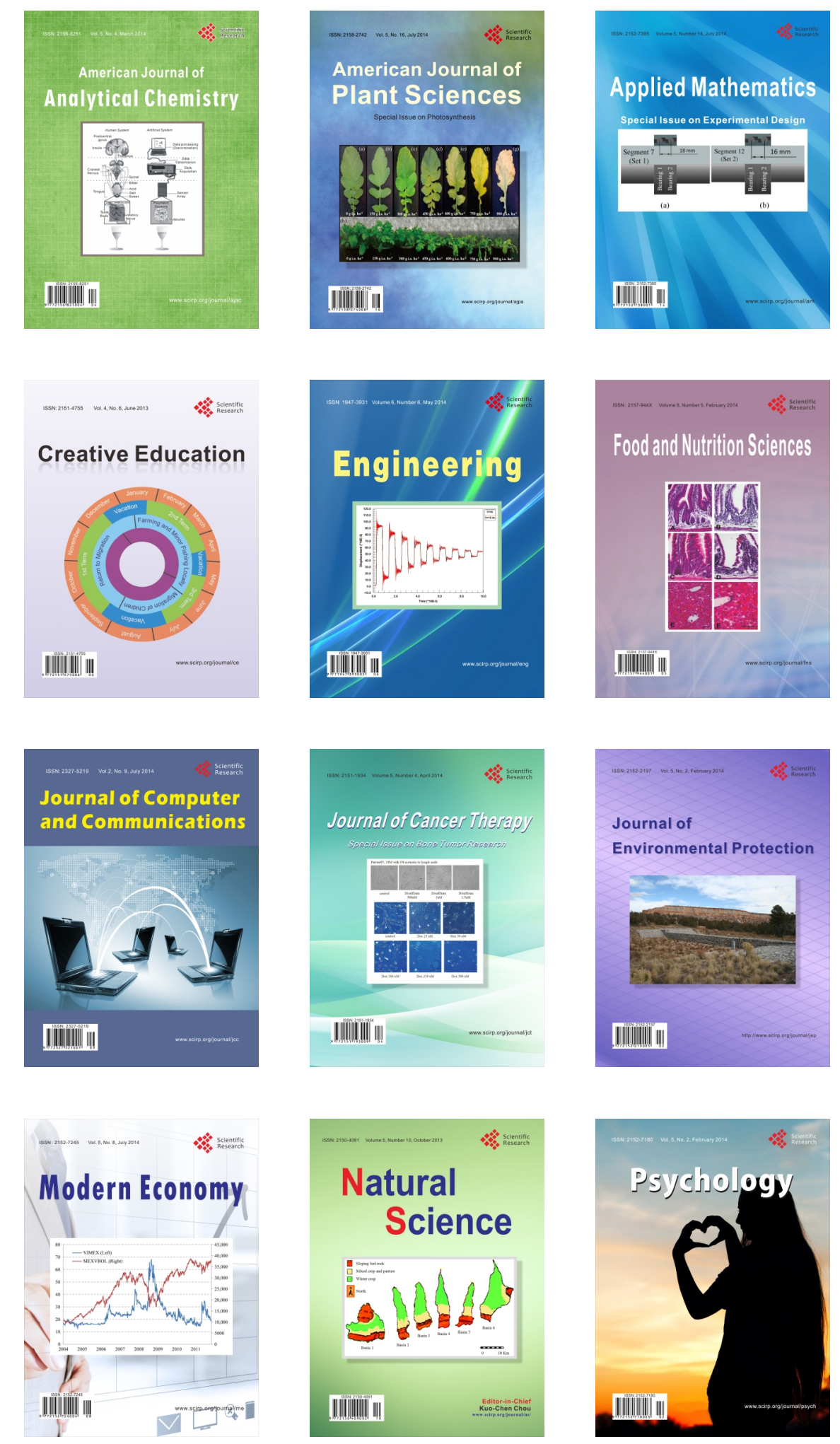